\title{
"You become a man in a man's world": is there discursive space for women in surgery?
}

Elspeth Hill ${ }^{1,2}$, Solomon $Y^{3}$, Dornan $T^{1,4}$, Stalmeijer RE ${ }^{1}$.

${ }^{1}$ School of Health Professions Education, Faculty of Health, Medicine and Life Sciences, Maastricht University, Maastricht, The Netherlands

${ }^{2}$ Division of Plastic and Reconstructive Surgery, Washington University in St Louis, Saint Louis, MO, USA

${ }^{3}$ Education and Social Research Institute, Manchester Metropolitan University, Manchester, UK

${ }^{4}$ School of Medicine, Dentistry and Biomedical Sciences, Queen's University, Belfast, Northern Ireland, UK

Word Count: 6,573 


\section{Abstract \\ Background}

The UK set a 2009 target for a $20 \%$ female surgical consultant workforce - in 2012, it remains $7 \%$. Studies have attributed this shortfall to the nature of a career in surgery and differing career aspirations among females. Rather than exploring barriers to participation, this study aims to explore the selfnarratives of those women who do undertake surgical careers and who do come to see themselves as surgeons.

\section{Methods}

The study comprises fifteen individual interviews with women throughout surgical careers, from aspiring to surgeons, to senior and retired surgeons. Data were explored via discourse analysis with $a$ priori themes derived from the literature on women in surgery and Holland et al.'s theoretical framework of Figured Worlds.

\section{Summary of Work}

Discourses of being a surgeon and discourses of being a woman existed in competition. Female surgeons figured surgery as a career requiring $100 \%$ dedication, as they did motherhood, though the demands of these two roles differed, and consequently were not discursively compatible. Many related powerfully negative experiences where their gender marked them out as 'other' within surgery. Women described how they were expected to show masculine traits as a surgeon, and the ways in which they could consequently become legitimate in the surgical world as a 'woman-surgeon'. They found creative ways to articulate how women in general, and feminine qualities in particular, enhanced surgery. Finally, some women engaged in identity work, termed world-making - the creative orchestration of discourses of surgeonhood and motherhood to be mutually sustaining.

\section{Conclusions}

There is little discursive space to be both a successful woman and a successful surgeon. Those who combine these two roles must either be innovative in refiguring either what it means to be a woman or what it means to be a surgeon; or they must author a new space for themselves, a powerful discursive process termed 'world-making'. 


\section{Introduction}

The increase in the proportion of women at medical school has changed the gender demographics of the medical profession. ${ }^{1}$ One specialty in which women remain under-represented despite this change is surgery ${ }^{2}$. Though the number of women entering postgraduate surgical training has increased, by the end of training few remain..$^{2-4}$ While this pattern exists in many countries, it is particularly marked in the UK. Here women represent $58 \%$ of medical students, $33 \%$ of core surgical trainees (postgraduate years 3-4), $16 \%$ of specialty surgical trainees (postgraduate years 5-10) and 7\% of fully-trained surgeons. ${ }^{2,4}$ Much of the literature examining this demographic phenomenon focuses either on factors affecting the career decisions of medical students, ${ }^{5-8}$ or on reasons why women do not pursue surgery. ${ }^{9-}$

${ }^{12}$ Yet, self-evidently, some women $d o$ engage in surgical careers. To further explore the reasons for women's under-representation, we focus this paper on those women who have decided to undertake a surgical career.

As women progress in surgical careers, they develop professional identities situated within the structure and culture of the surgical profession. Little literature exists on the relationship between gender and identity in surgical careers; however, parallels can be drawn between surgery and a number of other, previously studied, stereotypically masculine disciplines, for example mathematics, science and engineering, and business. ${ }^{13-15}$ Despite the widespread elimination of organisational and legal barriers to their advancement in these careers, women continue to be under-represented in traditionally male domains. This problem has been framed in terms of the lack of a discursive space for femininity in male-dominated arenas, where identities are typically masculine. ${ }^{15,16}$ Thus, women must position their femininity under a "cloak of invisibility". ${ }^{16}$ Yet there is evidence to show that some women in mathematics are finding new ways to be female within a predominantly masculine environment, via collective challenge to the engrained power dynamics and critical analysis of their own situation. ${ }^{15}$ The approach taken in mathematics, then, may be applied to examine the issue of women in surgery from a fresh theoretical perspective.

Holland et al.'s constructivist theoretical amalgam of Vygotsky, Bakhtin and Bourdieu is a lens through which we may explore women's identities in the 'figured world' of surgery. ${ }^{17}$ Identity is a word used to describe many different aspects of an individual, community or culture. Within Holland's 'Figured Worlds' framework, identity is not something that is possessed; rather, it is a constantly negotiated process that occurs between an individual and their social world. The theory of Figured Worlds captures the way in which individuals narrate ('self-author') their identities by selectively drawing upon the norms, values, language, practices and narrativised characters ('figures') of their particular social context. Hence, people 'self-author' their identities in dialogue with, and in response to, those around them, drawing on the shared sociohistorical meanings, or discourses, that are available to them. ${ }^{17-20}$ This concept of self-authoring affords a degree of agency - opportunity for selfdetermination - as individuals can selectively draw upon and position themselves within societal discourses; indeed, individuals have the ability to effect change within social worlds. ${ }^{17}$ Identity, then, may be considered a process of becoming; people are continuously shaping and being shaped by the world around them. Figured Worlds considers gender as part of identification, a stance it shares with poststructuralist feminism. ${ }^{17,21}$ From this perspective, it is culture, discourses and processes of identification that are of primary interest. This includes how gender interacts with and mediates these, but not solely how it does; it is the interaction and complex interplay of history-in-person and its interaction with the figured world that is the focus of analysis; gender emerges as a result of the performance of identity. When viewed as the point of intersection where past experiences and current practice meet, and the individual and society interact, ${ }^{17}$ identity allows us to examine gender issues in surgery at a micro and macro level simultaneously.

If we acknowledge that the interaction between identity and social structure is important, then the ways in which individuals navigate and negotiate this interaction are also important. The role of narrative in this process can be studied through discourse analysis, which describes the function of language as 
twofold: to support social activities and identities, and to support human affiliation within social groups, cultures and institutions. ${ }^{22}$ Surgery has multiple social groups, cultures and institutions with which to affiliate oneself, and there is a complex interplay of social activities and positions to negotiate, which may pose differing barriers to engagement for women. ${ }^{12,23,24}$ One example, The Royal College of Surgeons of England, is an organisation that is exclusive, steeped in history and traditionally masculine. Similarly, the culture within an operating theatre is hierarchical, regimented and closed to outsiders. ${ }^{25}$ In any figured world, social positioning, or positionality, is mediated by "on-the-ground relations of power, deference and entitlement, social affiliation and distance". ${ }^{17}$

Surgery as a practice is discursively masculine, privileging embodiment of masculine characteristics. ${ }^{26}$ How then do women experience this field, and author themselves in response to it? It may be that there is a lack of discursive space for women within the surgical world. This study aims to explore how those women who do undertake surgical careers and who do come to see themselves as surgeons experience these institutional environments, and how they use language to identify or disidentify therein. Hence, this study uses discourse analysis and the Figured Worlds framework to answer the research question: how do female surgeons self-narrate their identities?

\section{Methods}

\section{Research ethics}

Ethical approval for the study was granted by The University of Manchester Committee for the Ethics of Research on Human Beings (Ref: 11314). Detailed backgrounds of individual participants have been withheld to ensure confidentiality.

\section{Theoretical framework}

We undertook an in-depth qualitative study using Figured Worlds as a theoretical framework. ${ }^{17}$ This theory facilitated exploration of identity in two ways. Firstly, in terms of 'figured identity', i.e. identity pertaining to an individual's own experiences, the narratives of others, the figured world of surgery and its figures. This allows us to understand how individuals' pasts have influenced their identities, and how they imagine themselves and the world around them. Second, in terms of 'positional identity', i.e. identity pertaining to an individual's position within a social world in relation to others. This provides a tool to explore relationships, power and hierarchy. The use of Figured Worlds predisposes an epistemological stance: the way people choose to talk about themselves, particularly in relation to others, is the way they narrate their own self (to themselves as well as to others), and thus their identities. Therefore, by interviewing participants we can study their identities.

\section{Setting}

Medical student participants attended a large UK medical school with a five-year problem-based learning curriculum. All doctors were working, or had worked in hospitals within the UK National Health Service (NHS): junior doctors in their first two postgraduate years were undertaking a Foundation Programme in medicine, surgery and general practice, and applying to surgical training; surgical trainees were undergoing two years of core surgical training and at least a further five years of specialist surgical training; consultant (fully trained) surgeons were either currently practising or retired.

\section{Participants}

Sixteen women were invited to participate, comprising a purposive, cross-sectional sample of the surgical training pathway representing aspiring, training, fully qualified and retired surgeons (Table 1), including those who had undertaken both direct and more indirect routes through surgical training. All those who were approached agreed to participate, with one exception, giving a final sample of fifteen. The sample included participants with and without families, those working less than full-time, those who had taken time out for research or to have children, and surgeons from different sub-specialties. 


\section{Data collection}

Semi-structured individual interviews were conducted by EH at university or hospital sites. Interviews lasted a maximum of one hour, and were conducted with an interview guide derived from the literature and pilot interviews, informed by Figured Worlds. ${ }^{27}$ Interviews used open-ended questions to encourage participants to reflect on their experiences, thoughts and opinions on their career, as well as on surgery in general. Questions were designed to facilitate exploration of professional identities and important events, for example, "What does being a surgeon mean to you?" and "Have there been any moments when you felt you particularly belonged, or felt included in surgery? How about moments when you felt you didn't belong, or felt excluded?" Initially, issues of gender were allowed to emerge organically, then addressed more explicitly nearer the end of interviews. EH, at the time a senior medical student, and aspiring surgeon, conducted the interviews. Interviews were audio recorded, transcribed verbatim, and pseudonymised.

\section{Analysis}

Discourse analysis was undertaken, in accordance with Gee, with a priori themes drawn from the literature on women in surgery, coupled with theoretical themes from Figured Worlds to act as sensitising concepts. ${ }^{1722}$ Common themes arising from the data were initially coded by $\mathrm{EH}$, with transcripts read and re-read by the entire research team to challenge previous interpretations of the data. As new themes emerged, the analysis was adapted in an iterative process. To ensure analytical rigour, interview transcripts were coded separately, then collaboratively, to highlight any differences and similarities between interpretations. Additionally, a sample of data was re-coded by a researcher outside the research team and compared to the analysis. ${ }^{28}$

\section{Reflexivity}

Epistemologically, this work acknowledges that data were co-constructed between the interviewer and interviewees. ${ }^{27}$ Therefore, the research team were cognisant not only of how the researcher positioned the participant, but also of how interviewees responded to and positioned the researcher. In response to this, EH maintained reflexivity via a reflexive diary, in which she recorded any preconceived ideas about the data and topic. Throughout data collection and analysis, she recorded further reflections with the potential to influence analysis. The diary was regularly discussed within the research team. Further, EH kept detailed records that focused specifically on critical reflexivity of the dataset, considering not simply whom the interviewee was answering or addressing, but whom EH, as researcher, was answering and addressing, and which shared discourses were drawn upon, by whom and with what result. 


\section{Results}

\section{Competing discourses of being a surgeon and being a woman}

The female surgeons interviewed identified very strongly as surgeons. Yet being a surgeon and being a woman were competing components of their narratives; thus, when narrating their identities as surgeons, they always gave a parallel, and often unprompted, account of themselves as women.

Elspeth: "Do you think being a surgeon is a big part of who you are?

Helen: I suppose it, it has to be. I think it has to be because I, when I trained, when I qualified, we used to do eighty to a hundred hours a week,... So I've worked long hours and that, that's been me, you know. Erm, it's been the major part of my life. If you're working seventy, eighty hours a week for something, it is your life, you're sleeping some of it, aren't you? Yes. It doesn't leave room for much else. I do think nowadays that people have outside interests and other things and their job, their medicine is a small part of their life, quite often, but it has been my whole life. I suppose I've given my life to it, really. I don't know if you want to hear about marriage and husbands and things but, as you know, I'm not married, I've not got a husband, I've not got children. Erm, I haven't sacrificed anything, I've never said to somebody, "No, I'm not marrying you because I'm a surgeon." The opportunities haven't come; there hasn't been anybody I've wanted to marry. But as a consequence of that I put my time into my work... And even as a consultant I would stay late at night and look at results and things... Because it's the way I've always done it. And I also put a lot of time into it, a lot of extra time into it. So yes I am who I am because, you know, I am a surgeon and that's me. You can't separate it from me."

Helen, retired consultant surgeon

Here, Helen discusses her dedication to surgery and offers an unbidden account of the reasons she did not marry or have children. Her narrative draws on a discourse of surgeonhood as the core of a person; implicit is that being a surgeon means there is little space for anything else. Her narrative demonstrates how directly the discourse of being a surgeon competes with the discourse of being a woman, and the simultaneous but contradictory requirement for female surgeons to be both. For women surgeons, without direct juxtaposition of accounts of themselves as women, it would sound as if they had given up that part of themselves; to give an account of oneself solely as a surgeon equated to an account of oneself as lacking as a woman, particularly in terms of family life. In the next quotation, Sarisha prefaces her strong identification as a surgeon with an account of her motivation to fulfil female roles in family life - again demonstrating that female surgeons must answer to both these discourses.

"I want to be a good, you know, daughter, a good wife, a good sister, a good surgeon...I don't just see myself as a doctor, I see myself as a surgeon... I wouldn't say it's the be all and end all but it's pretty much getting there... *laughter*... It's almost everything. I couldn't see myself doing anything else. And if somebody told me I couldn't operate I'd be truly gutted."

Sarisha, mid-level surgical trainee

The discursive competition between being a surgeon and being female was also apparent in the narratives of the aspiring female surgeons.

“And obviously particularly from a female's point of view, erm, you know, a plan one day - getting married, having children, having a family, but I don't see where that could fit in. I have difficulty seeing where that could fit in sort of when I'm, you know, 35 and doing on-calls and quite crazy hours."

Zaineb, 4th year medical student

Kate, a first year student, struggles to articulate a critique of the discourses regarding women in surgery. Importantly, she acknowledges that women who "don't want a family" are seen as "really 
weird", and implicitly, that there are differing expectations of female surgeons when compared to their male counterparts.

“...the stereotype of all the ... women that are surgeons... they're really hard women ... people think that women that don't want a family or children straightaway are kind of really weird, erm... like, because no-one looks at a male surgeon as, like, "Oh, I wonder if they've had a family or not.",

Kate, 1st year medical student

Even at her early stage in medical school, and despite her strong interest in surgery, Kate has formulated an understanding that being a surgeon and being a woman are difficult to combine, if not at odds, yet she resists this: no one asks these questions of men.

\section{Irreconcilable discourses of being a surgeon and being a mother}

Central to the discourse of surgeonhood was complete dedication to the role, most notably in terms of time - working "full time", "doing all the on call". Dedication was also important in the discourse of motherhood, for example "being there for bedtime". Attempting to operate within these competing discourses, Jane articulates that the roles are "kind of mutually exclusive"; there is very little space, in both discursive and practical terms, to be a good surgeon and a good mother. To compromise on either was tantamount to failure in the role: Carolyn contemplates compromising the "respect" of her colleagues by working part-time, while Jane discusses feeling "guilt" as a mother by working full-time.

“...there are still men in my peer group who will never respect a female surgeon unless she's full time, doing all the on call, not going off to see the kids in the Christmas play, you know, unless she's a fully-fledged bloke. There's a man in my department who said, "Carolyn, I'll never respect you because you didn't do it the way we did it."... and it's not very long ago that he said that either."

Carolyn, consultant surgeon

Here, Carolyn is defiant in her tone, recognising the injustice inherent in the discursive competition between being a surgeon and being a woman. Worse than embodying opposing discourses as a female surgeon, being a mother and a surgeon require enacting mutually exclusive discourses, leading to competition for a female surgeon's time and attention in a very real sense. Jane, like Carolyn, recognises and resists the competing and unjust nature of the expectations of her as a surgeon and as mother; indeed she contrasts this with expectations of working fathers.

"I don't think many fathers are at home stressing that they're really bad at work because they're... fathers. I think it's more, it is more of a woman thing and I think, a mum thing... And a lot of women feel very guilty about things all the time which, usually unnecessarily, you have to say... So you've just got to get rid of that whole guilt thing as well. That's how it works for me. I think quite a few people have said that they do feel guilty when they're at work or if they're working late at work, which I thought was interesting. I'm sure most do actually..."

Jane, junior consultant surgeon

Hence, both Carolyn and Jane recognise the injustice that, discursively, a woman cannot be a good mother if she is a surgeon. Although Jane and Carolyn's resistance offers a challenge to discourses of being a surgeon and being a woman, their narratives still operate within these discourses. Indeed, Jane cannot maintain her stance of resistance; the competition between these discourses influences the way she feels about herself as a mother.

"...I mean there has been the odd time when... when have I felt bad? Erm, sometimes you can have just a really busy week and it's just, erm, for example, I don't go away much now with work. I, I just try not to do it and I don't have to do it but, erm, a couple of weeks ago I went away and I 
stayed overnight and I really don't like doing that because I feel, erm, I feel... I like to be there at bedtime, I like to be there when they wake up so I felt a bit bad about that, erm, not bad enough not to do it because I do it about once every, oh God, probably not even once a year. So no it's not a frequent thing... Hmm. I mean, I'm, I'm home for... I put the kids to bed most nights, pretty much every night really..."

Jane, junior consultant surgeon

\section{Positioning by others}

As well as negotiating a position for themselves within these discourses, female surgeons were aware of how they were positioned by others - particularly in terms of the expectations placed on them as a surgeon and as a woman, both by those within surgery and those without. Here, Jane discusses how being a surgeon had been met with surprise both from patients at work, due to her gender, and from other mothers outside work, due to her career. Notably, such occurrences caused her to reflect on how, as a 'female surgeon', she fitted neither the figured world of surgery nor the figured world of the middle-class mother.

"I mean, I've had over the years [patients] come in and say to me, "Oh you're not, you're not what I expected," or, “You're not... you don't look like a surgeon,"... So they, people do have a perception... and it is to do with gender...

...I still now will go out and, again, not talk to anyone and they'll say, "What do you do?" and you tell them and you still get a moment of, "Oh my God!'”... say I'm out with my kids on what I call my mummy days so I wear my jeans looking like any other mum and, erm, I think after, you know, especially amongst the school mums there's... a perception that you don't work at all so that when you say you, you do work and they ask you what you do, then I, I suppose it's completely not what they're expecting so there's this element of surprise."

Jane, junior consultant surgeon

Female surgeons were also positioned by their colleagues within the world of surgery: Leah describes how senior doctors had repeatedly attempted to steer her out of surgery, explicitly explaining that she did not fit with their understanding of a surgeon.

"Seniors... they didn't see me in surgery because they felt that I was too sociable a person, you know, and not driven enough... they could see me, you know, being a GP [general practitioner] or an anaesthetist... so there were a few times people said things like that but nobody ever specifically said don't do it, you know... I think that's what people probably saw in me as well, was that actually I like to go home at the end of the day and switch off, you know I have my hobbies that I do and I go out and do them. And I think probably that's what people recognised in me, you know, that maybe they didn't think that I had the motivation to then start studying when I needed to."

Leah, senior surgical trainee

Leah's narrative illustrates how the strength of the discourse of a surgeon, and the more powerful status of those who fit it, act to render such interventions by seniors more or less acceptable as "careers advice'; though Leah feels a sense of injustice at the interventions, she understands clearly why they occurred. However, some positioning by seniors was particularly unacceptable.

“...people go for a drink after work... and there would be a couple of consultants there... but I remember going in one time, my consultant was sitting at the bar with his double gin and tonic and his fawning registrar and a couple of... you know, other people round. And I rushed along and I was, you know, a nice pencil skirt and I was... because like, erm, I had just passed FRCS [Fellowship exam of The Royal College of Surgeons] so I was in my jacket rather than a white coat, you know. So a nice silk shirt, and as I rushed in, you know, with my, you know, really nice, really 
like crisp kind of... and he just stared at my, my chest and said, er, "Oh cold out there, is it?" I just thought, that's my boss and he can't even hold it in, you know. And he, he... just, you know, and I'm still referring him patients; he's still in the same neck of the woods."

Juliette, senior consultant surgeon

Here Juliette's narrative describes another account of the exercise of power by seniors in the figured world of surgery. Her increased legitimacy in surgery, conferred by success in the fellowship exam, is undermined by her male boss who, through sexualisation, repositions her as inferior by drawing attention to her gender. Some, notably the most senior surgeons, had had such terrible experiences that, though they were long past and rarely discussed, continued to be an important part of their identities. Yet these formative negative experiences were often carried as mantles and drawn on as a source of strength, becoming refigured - changing in their meaning over time as these women's understanding of themselves and their lives changed. They became part of their narrated selves in a dialogic sense dialogically opposed but mutually sustaining - providing the negative from which they constructed the relief of their own practice. Here, Jane narrates how she has developed her own way to mentor trainees borne of negative experiences during her training.

"I tend to be around quite a lot so I see the trainees quite a lot, erm, and I'd like to think I'm quite easy to talk to or approach. I, I would hope I'm quite approachable and if they had a problem they would feel it's okay to, to come and talk to me... and not, you know. Again, I've worked with people who... when I was a trainee who, you know, er, seemed to have this kind of, erm, fear thing going on - you know, everyone was absolutely petrified of them or they would never approach them or, you know..."

Jane, junior consultant surgeon

Rather than drawing on the previously dominant training discourse of detachment and authority through seniority, Jane attempts to build more collaborative relationships.

\section{Identity work as a female surgeon}

\section{Downplaying feminine aspects of identity}

Some women consciously undertook 'identity work' in order to 'hide' certain parts of themselves in order to have legitimacy within surgery. Leah does not discuss her children at work, because of the threat she feels that being positioned as a mother and a woman in that context would compromise her position within the figured world of surgery.

Leah: "I think the difference is not so much being a female, it's having kids... Very, very much so, because before I had my baby I wouldn't have said there was any difference at all... When you're going for consultant jobs they do look at you as if to say, "You're just going to have babies and go and work part-time", you know, this sort of thing. But after having my kid, you see it more and more, that people do think... you know, that you're going to disappear off and do the childcare run and things.

Elspeth: Even though you've been working full-time?

Leah: Oh yeah, yeah. And you do, you very, very consciously don't talk about your kid at work. ...if we were doing something that was a bit more accepting of women having kids, then it would be different, but, erm, I very consciously don't talk about my kid, very consciously. If I've got issues with childcare I sort it with my husband and don't bring it to work. So, erm, no I don't think there's any bias to work, but women who want to have kids? Yes.

Elspeth: And will you deal with it by consciously just not, erm...?

Leah: You become a man in a man's world, definitely that way, yeah, which is weird and I 100\% wouldn't have said that at all before having kids but, erm, yeah that's, that's the big difference, definitely." 
For Leah, having children made distancing herself at work from feminine discourses much more difficult and, simultaneously, imperative. She overcomes this - thereby undertaking 'identity work' by not talking about her child in a work context, and hiding her identity as a mother under a 'cloak of invisibility'. Leah undertakes identity work in order to maintain her discursive position within surgery, including actively hiding her motherhood. However, this was not the only form of identity work undertaken by female surgeons.

\section{Refiguring the good surgeon}

Female surgeons also creatively refigured what it was to be a good surgeon. Sarisha's refiguring extends the discursive ideal of a surgeon to include aspects that she feels female surgeons can offer over their male counterparts. Notably she can make no concession to inferiority in dialogue with the discourse of the male surgeon; female surgeons are still "doing the same thing" as male surgeons, but with added extras. This conveys legitimacy to the discursive refiguring, being firmly rooted in the existing masculine discourse of an ideal surgeon.

"I think women are good surgeons. I think a lot of us pay a lot of attention to detail and I think it's really important. I think we have a lot to offer in the way that we interact with patients, you know, erm, in what we can offer skill wise. I think it's, it's different."

Sarisha, mid-level surgical trainee

Emily draws on the figure of a male supervisor who, for her, combined success in surgery with empathy for patients and surgeon colleagues.

“...my supervisor... was just an absolute gem; he's such a lovely man. And I think he's not just lovely with the patients, he's really interested in training as well. Erm, so I guess he inspired me a lot to do surgery and also probably dispelled the notion for me that, to be a surgeon... you have to be, you know, a not very nice person, but you can actually be a nice bloke or a nice, you know, a nice person, be empathetic with your patients and still get ahead..."

Emily, junior surgical trainee

She narrates her own identity in dialogue with the figure of a male surgeon. Notably she uses her perceptions of her supervisor, with whom she can herself identify, to broaden her account of being a surgeon to include more feminine priorities.

\section{World-making}

Rather than aligning with or rejecting existing discourses, some women orchestrated discourses to try to articulate a totally new discursive space to be a surgeon and female, actively positioning themselves (rather than passively being positioned) within new spaces in which their previously conflicting identities could co-exist. The gendered nature of surgical identity meant that women were always positioned as 'other' within the surgical world, specifically as a "female surgeon" or "woman surgeon". Emily articulated how liberating it might be to simply be seen as a "surgeon".

"I hope it will get to a point where, that, you know, people don't see you as a woman surgeon; they just see you as a surgeon. But I think at the moment people would still see you as a woman surgeon... If that makes sense. I hope it just gets to the point where it doesn't matter that you are a woman, that you are just seen for being a surgeon and that's no different from being a male surgeon... that people will, erm, sort of be, er, judged or be looked at for their surgical skill rather than their gender. That's, that's the dream! *Laughter*."

Emily, junior surgical trainee 
Though she is unable to describe its detail, Emily imagines an alternative figured world, where she is judged purely on her ability to do the job without her gender colouring the way she is seen. Jane takes this imagined world further to articulate her own act of 'world-making' - the creative orchestration of discourses to transform the existing figured world of surgery - by discussing how the similarities between motherhood and surgeonhood worked in practice.

"I actually think having kids... it's, kind of, similar to having patients in some ways... The way you, you look after your, your family, the way you organise things, your priorities, is the same as when I'm at work... i.e. when I'm at home the thing that really matters is my children and when I'm at work... your priority is, is, is your patients. So it's a similar kind of mindset and the skills you need as a, as a, as a mum are quite... there's quite a lot of crossover to, to being a surgeon - being able to organise, being able to, to delegate, erm, making decisions, getting up in the middle of the night, having a lot of energy. All those things are quite... you know, there is, there is a bit of overlap there between the two."

Jane, junior consultant surgeon

Jane creatively aligns the skill-sets of mother and surgeon in a mutually strengthening way, rather than in opposition, positioning herself more positively within the existing discourses and at the same time creating a new discursive space. World-making is a discursively powerful phenomenon, enabling these women to re-narrate their feminine and surgical identities as mutually compatible, building upon each other in a complementary and strengthening way.

\section{Discussion}

Discourses of being a surgeon competed with discourses of being a woman. The female surgeons figured surgery as a career requiring $100 \%$ dedication, as they did motherhood, though the requirements of these two worlds were seen as differing. Consequently these roles were not discursively compatible, and each participant told of experiences where their gender marked them out as 'other' within the surgical world. Some had had powerfully negative, even traumatic, experiences, yet had refigured these and drew upon them as sources of strength, discursively creating a position for themselves far away from what had hurt them. Women described the masculinity expected of them as a surgeon, and the ways in which this was experienced and negotiated to be legitimate in the surgical world as a 'woman-surgeon'. They also found creative ways to feminise what it was to be a 'good surgeon', discursively moving it away from the traditionally masculine archetype to articulate how women in general, and feminine qualities in particular, enhanced surgery. Finally, some women engaged in powerful identity work, termed world-making - the creative orchestration of the discourses of surgeonhood and motherhood so they were no longer mutually exclusive, but instead became mutually sustaining.

Most research in the area of women in surgery has focused on barriers to participation. Here, we have considered the issue from the perspective of those who do undertake surgical careers. We have demonstrated how women draw on gendered experiences of surgery to self-author their identity as surgeons, and, importantly, how such experiences may be refigured to further support their selfnarration as a female surgeon. This further builds on anthropological studies that explored the masculine culture of surgery. ${ }^{29}$ Indeed, the very title of Cassell's seminal work 'The Woman in a Surgeon's Body' indicates the masculine nature of surgery, its mismatch with womanhood and the discursive discomfort in female surgeons' narratives of occupying this role as a woman.

Although tensions existed between being a woman and being a surgeon in these narratives, the greatest incompatibility pertained to combining motherhood and surgery. This adds to demographic work showing female surgeons are less likely to have children..$^{30}$ The incompatibility was not only manifest in cultural or identity terms, but also in practical terms of time: with 'presentee-ism' discursively integral to showing dedication to these two roles. This was compounded by the discursive impossibility 
of doing both things at once: self-identifying as a good surgeon (by putting in the extra hours) and as a good mother (by reliable attendance at bedtime) was extremely challenging. In the figured world of surgery the competing discourse of efficiency and of each team member giving their all outweighed the more feminine 'caring' contributions, that women could bring to surgical practice. A recent paper considered this discursive conflict between the masculine 'efficiency' and the feminine 'care' within medicine in general, concluding that, as both are undoubtedly important, they should not be considered in opposition. ${ }^{1}$ While one discourse is ranged against the other (and winning) women having children will continue to be figured as an obstacle in the surgical world.

Although Figured Worlds has not been widely employed in the medical education domain, women have been found to undertake similar 'identity work' in mathematics. ${ }^{15,31}$ Female mathematicians undertook world-making through collaboration, subverting the traditionally independent practice of mathematics and, in doing so, they self-authored strong identities as mathematicians which did not exclude being female. Our analysis, therefore, has implications beyond how women form their identities in the masculine domain of surgery; by employing a novel theoretical analysis we have learned something of experience and identity formation of minorities operating within a prevailing discourse that excludes a major part of their identities. If we understand how a subset from within a minority group survive, develop and flourish within a culture in which they are disprivileged and 'othered' then, by making explicit the ways in which they do this, we can herald innovative ways to support these groups to succeed in domains previously 'out of bounds' to them.

In our purposive sample, all participants studied or worked in the UK, capturing rich narratives of women from a variety of backgrounds and training grades, and also their reflections on past and future times. The data, however, can make only limited claims to generalisability in terms of participants' experiences of surgery. There may have been factors specific to the research setting that influenced responses, for example, the UK has a prominent national organisation called 'Women in Surgery', to which many participants referred, and which may have primed discussions of gender issues. Equally, British surgery is steeped in history, which largely reinforces the prevailing masculine discourses; for example, historic peculiarities in the titles of surgeons, who give up being a ' $\mathrm{Dr}$ ' to become a ' $\mathrm{Mr}$ '. This leaves female surgeons to opt for 'Miss', 'Mrs' or 'Ms', each carrying connotations of marital status, and marking them out as 'other' simply by not being a 'Mr'.

Our analysis was strengthened by the complementary expertise and perspectives of a medical student, senior doctor and education researchers. This facilitated creative disturbances and enhanced analysis. ${ }^{28}$ Interviews were carried out by a single individual (EH). As a senior medical student 'insider', she shared with participants a significant understanding of the surgical world. While this may have afforded her deeper access to participants' experiences, it is also possible that some understanding remained implicit during interviews. Therefore different data and subsequent analysis may have arisen had the interviews been conducted by someone of another background.

The theoretical framework of Figured Worlds was a powerful tool with which to explore issues of identity and agency within the figured world of surgery. ${ }^{17}$ While we used Figured Worlds to explore how women in surgery self-narrate their identities, a future study could investigate attrition and the narratives of those women who have left a surgical career. Given that being a surgeon was so important to the identities of our participants, such a study would to gain insight into factors which influence a woman's decision to 'drop out' and how they construct an identity from that position. A further point of interest in our data was how the narratives included 'figures' - narrated real 'embodied' or symbolic personas of surgeons that existed for our participants. These figures were used dialogically within their narratives to construct identity, perhaps by their use as role models or villains. A future study could therefore explore how figures are used by women in surgery to construct their identities within that world. 
Our work has practical implications for surgical education. The data show that discursive positioning is powerful, and could be orchestrated in the media, policy or in conversation for the advancement of women in surgery. We provide evidence of female surgeons' undertaking 'world-making' - refiguring existing practices to become more inclusive. Women's participation is, in itself, indicative of change; cultures $d o$ shift. Initiatives might not directly change cultures but they do present the possibility of discussion and make spaces for new discourses to emerge; they provide a language of description if not immediate change. There may also be great value in creating supportive relationships between individuals in under-represented groups to facilitate such activities ${ }^{10,32,33}$, which may provide evidence for initiatives such as the UK's 'Women in Surgery'. However, the impact of such initiatives may be limited because it is not easy to directly change cultures; change may arise more organically from the actions of individuals, who creatively identify and 'world-make' from inside a culture. What is clear from these data is that discursive innovation is required to challenge prevailing discourses of surgical practice, so we can better value and support those women who do undertake a surgical career.

\section{Conclusions}

There is little discursive space to be a successful woman and a successful surgeon. Those who do combine these two roles must either be innovative in refiguring what it means to be a woman or what it means to be a surgeon; or they must author a new space for themselves, a powerful discursive process we term 'world-making'. 


\begin{tabular}{|c|c|c|}
\hline $\begin{array}{l}\text { Pseudon } \\
\text { ym }\end{array}$ & Grade & Sample Group \\
\hline Kate & 1st year medical student & \multirow{2}{*}{$\begin{array}{l}\text { Aspiring female } \\
\text { surgeons: }\end{array}$} \\
\hline Christina & 2nd year medical student & \\
\hline Michelle & 3rd year medical student & \multirow{4}{*}{$\begin{array}{l}\text { Contemplating } \\
\text { whether to 'opt in' to a } \\
\text { surgical career }\end{array}$} \\
\hline Zaineb & 4th year medical student & \\
\hline Indira & 5 th year medical student & \\
\hline Nadia & $\begin{array}{l}\text { 1st year postgraduate } \\
\text { doctor }\end{array}$ & \\
\hline Laura & $\begin{array}{l}\text { 2nd year postgraduate } \\
\text { doctor }\end{array}$ & \multirow{5}{*}{$\begin{array}{l}\text { Surgical trainees: } \\
\text { Deciding whether to } \\
\text { 'opt out' or continue } \\
\text { training in surgery }\end{array}$} \\
\hline Emily & Junior core surgical trainee & \\
\hline Anna & $\begin{array}{l}\text { Junior specialist surgical } \\
\text { trainee }\end{array}$ & \\
\hline Sarisha & $\begin{array}{l}\text { Mid-level specialist surgical } \\
\text { trainee }\end{array}$ & \\
\hline Leah & $\begin{array}{l}\text { Senior specialist surgical } \\
\text { trainee }\end{array}$ & \\
\hline Jane & Junior consultant surgeon & \multirow{4}{*}{$\begin{array}{l}\text { Fully qualified } \\
\text { surgeons: }\end{array}$} \\
\hline Carolyn & Consultant surgeon & \\
\hline Juliette & Senior consultant surgeon & \\
\hline Helen & Retired consultant surgeon & \\
\hline
\end{tabular}

Table 1 - Participants by career grade 


\section{References}

1. Bleakley A. Gender matters in medical education. Med Educ. Blackwell Publishing Ltd; 2013;47(1):59-70.

2. McNally SA. Surgical Training: Still Highly Competitive But Still Very Male. Bull R Coll Surg Engl. The Royal College of Surgeons of England; 2012;94(2):53-5.

3. Davis EC, Risucci DA, Blair PG, Sachdeva AK. Women in surgery residency programs: evolving trends from a national perspective. J Am Coll Surg. 2011;212(3):320-6.

4. Center for Workforce Studies. 2012 Physician Specialty Data Book. Washington, DC: Association of American Medical Colleges; 2012.

5. Burack JH, Irby DM, Carline JD, Ambrozy DM, Ellsbury KE, Stritter FT. A study of medical students' specialty-choice pathways: trying on possible selves. Acad Med. 1997;72(6):534-41.

6. Drinkwater J, Dornan T, Tully MP. The effect of gender on medical students' aspirations: a qualitative study. Med Educ. 2008;42(4):420-6.

7. Maiorova T, Stevens F, Scherpbier A, van der Zee J. The impact of clerkships on students' specialty preferences: what do undergraduates learn for their profession? Med Educ. 2008;42(6):554-62.

8. Cleland J, Johnston PW, French FH, Needham G. Associations between medical school and career preferences in Year 1 medical students in Scotland. Med Educ. 2012;46(5):473-84.

9. Baxter N, Cohen R. The impact of gender on the choice of surgery as a career. Am J Surg. 1996;172(4):373-6.

10. Neumayer L, Kaiser S, Anderson K. Perceptions of women medical students and their influence on career choice. Am J Surg. 2002;183(2):146-50.

11. Yu T-C, Jain A, Chakraborty M, Wilson NC, Hill AG. Factors influencing intentions of female medical students to pursue a surgical career. J Am Coll Surg. 2012;215(6):878-89.

12. Hill E, Vaughan S. The only girl in the room: how paradigmatic trajectories deter female students from surgical careers. Med Educ. 2013;47(6):547-56.

13. Meriläinen S, Tienari J, Thomas R, Davies A. Management Consultant Talk: A Cross-Cultural Comparison of Normalizing Discourse and Resistance. Health. 2004;11(4):539-64.

14. Regan E, Dillon J. Undergraduate students' narrations of gender and choice ? a focus group study. Proceedings of the HEA STEM Learning and Teaching Conference. London: The Higher Education Academy; 2012.

15. Solomon Y. Finding a Voice? Narrating the Female Self in Mathematics. Educ Stud Math. 2012;80(2):171-83.

16. Walls F. Whose Mathematics Education?: Mathematical Discourses as Cultural Matricide. Critical Issues in Mathematics Education. Missoula, MT; 2009. pp. 45-52.

17. Holland D, Lachicotte W Jr, Skinner D, Cain C. Identity and Agency in Cultural Worlds. London: Harvard University Press; 1998.

18. Bakhtin MM. The dialogic imagination: four essays. Austin, TX: University of Texas Press; 1981. 
19. Bakhtin MM. Speech genres and other late essays. Emerson C, Holquist ME, eds. Austin, TX: University of Texas Press; 1986.

20. Monrouxe LV. Identity, identification and medical education: why should we care? Med Educ. 2010;44(1):40-9.

21. Butler JP. Gender Trouble. 2nd ed. London: Routledge; 2007.

22. Gee JP. An introduction to discourse analysis: Theory and method. 2nd ed. London: Routledge; 2005.

23. Hill E, Bowman K, Stalmeijer R, Hart J. You've got to know the rules to play the game: how medical students negotiate the hidden curriculum of surgical careers. Med Educ. 2014;48(9):884-94.

24. Hill EJR, Bowman K, Stalmeijer R, Solomon Y, Dornan T. Can I cut it? Medical students' perceptions of surgeons and surgical careers. Am J Surg. 2014;208(5):860-7.

25. Lingard L, Reznick R, Espin S, Regehr G, DeVito I. Team communications in the operating room: talk patterns, sites of tension, and implications for novices. Acad Med. 2002;77(3):2327.

26. Riska E, Novelskaite A. Gendered Careers in Post-Soviet Society: Views on Professional Qualifications in Surgery and Pediatrics. Gender Issues. 2008;25(4):229-45.

27. Gee JP. How to do Discourse Analysis. London: Routledge; 2011.

28. Fairclough N. Language and Power. 2nd ed. London: Pearson Education; 2001.

29. Cassell J. The Woman in the Surgeon's Body. London: Harvard University Press; 2000.

30. Halperin TJ, Werler MM, Mulliken JB. Gender differences in the professional and private lives of plastic surgeons. Ann Plast Surg. 2010;64(6):775-9.

31. Solomon Y, Lawson D, Croft T. Dealing with "fragile identities": resistance and refiguring in women mathematics students. Gender and Education. 2011;23(5):565-83.

32. Sanfey HA, Saalwachter-Schulman AR, Nyhof-Young JM, Eidelson B, Mann BD. Influences on Medical Student Career Choice: Gender or Generation? Arch Surg. 2006;141(11):1086-94.

33. Drolet BC, Sangisetty S, Mulvaney PM, Ryder BA, Cioffi WG. A mentorship-based preclinical elective increases exposure, confidence, and interest in surgery. Am J Surg. 2014;207(2):179-86. 